\title{
PAISAJE E IDENTIDAD EN LA SIERRA ANDINA: LITERATURA Y FOTOGRAFÍA
}

\author{
GUSTAVO FIERROS \\ University of Denver \\ gustavo.fierros@du.edu \\ ORCID: 0000-0002-3331-1230
}

\section{RESUMEN}

El paisaje de la sierra andina ha sido una constante presencia no sólo en el arte y en la literatura peruana, sino también en los discursos de representatividad estética e identitaria en el Perú. Su aparición coincidió con el desarrollo de la fotografía, con el desarrollo del turismo en la región andina, así como con el indigenismo peruano. Este trabajo sostiene que tanto la construcción del paisaje de la sierra andina como de la imagen del indio en la obra del fotógrafo Martín Chambi, aunque son imágenes opuestas a las propuestas por José De la Riva Agüero y por Mariano Iberico, son, por otro lado, similares: imágenes a-históricas de la identidad indígena en la sierra peruana.

PALABRAS CLAVE: Martín Chambi, José de la Riva Agüero, Mariano Iberico, indigenismo, fotografía, literatura, paisaje, Perú, identidad.

\section{LANDSCAPE AND IDENTITY IN THE ANDEAN MOUNTAINS: LITERATURE AND PHOTOGRAPHY}

\section{ABSTRACT}

The Andean landscape has been a constant present not only in peruvian art and literature, but also in the national discourses of social identity. The consolidation of an Andean landscape coincides with the early development of Photography, as well as with the start of tourism at the turn of the 20th century, but also with the movement of Indigenismo. This paper argues that the consolidation of the Andean Landscape as well as the image of the Indio in the works of Martin Chambi, although different in many aspects to those of the limeño writers José De la Riva Agüero and Mariano Iberico, are, at the same time, similar: a-historical images of the indigenous identity in the Andean region of Perú.

KEYWORDS: Martín Chambi, José de la Riva Agüero, Mariano Iberico, indigenism, photography, literature, landscape, perú, identity.

\section{INTRODUCCIÓN}

Landscape is a natural scene mediated by Culture. It is both a represented and presented space, both a signifier and a signified, both a frame and what a frame contains, both a real place and its simulacrum, both a package and the commodity inside the package.

W. J. T. Mitchell

...He escudriñado con la lente de mi máquina fotográfica todos los rincones de los palacios y fortalezas del Cuzco; toda la región en que floreció el Imperio. Aquí están las escenas de 
hoy. Aquí el mestizaje colonial. Me gustaría que los testigos imparciales y objetivos vieran este acervo. Me siento como representante de la raza. Ella habla en mis fotografías.

Martín Chambi

El paisaje de la sierra andina ha sido una constante presencia no sólo en el arte y en la literatura peruana del siglo XX sino también en sus representaciones históricas y sociales. Podría decirse que es un invitado más o menos reciente a los discursos de representatividad estética e identitaria en el Perú. Su aparición, su visibilidad, coincide no sólo con el desarrollo tecnológico de la fotografía y su independencia como forma artística, sino también con el desarrollo del turismo en la región andina, y con una rica, compleja y hasta contradictoria corriente de pensamiento que se conoce como Indigenismo, ${ }^{1}$ y que el contexto peruano podemos ubicar hacia 1888 en los escritos de Manuel González Prada. El propósito de este trabajo es analizar y establecer una relación entre tres «textos» sobre el paisaje andino y su repercusión en el proceso de construcción de identidad nacional en el Perú contemporáneo: En la literatura y la reflexión, Paisajes Peruanos, de José de La Riva Agüero (1955) y Notas sobre el Paisaje de la Sierra, de Mariano Iberico (1973); y en el ámbito la fotografía, la obra de Martín Chambi (1891-1973). En concreto, este trabajo sostiene que la construcción de la imagen del indio en Chambi es diametralmente opuesta a las imágenes propuestas por José De la Riva Agüero y por Iberico; pero que su constitución lógica es, por otro lado, similar en los tres: una imagen a-histórica y mítica de la identidad indígena.

Un breve panorama histórico sobre la idea de paisaje ayudará a contextualizar el entendimiento actual que damos a este concepto. Este panorama, en el contexto latinoamericano, puede limitarse a los inicios del siglo XIX, época de la influyente enunciación de la naturaleza americana realizada por el viajero alemán Alexander von Humboldt. No está en duda el lugar fundacional que sus viajes y sus escritos ocupan en la creación y promoción de un imaginario sobre la América antes de que ésta se dividiera en Américas y el sur se identificara como latino. (Mignolo: 2008: 57, 2011: 106). Muchas de sus descripciones o imágenes se incorporaron no sólo a la visión europea de la época sobre lo que entonces se llamaba América o todavía Nuevo Mundo o Indias Occidentales, sino también a los discursos nacionalistas de las naciones emergentes en el continente americano, y muchas de esas imágenes aún perduran. ${ }^{2}$ Luego de las prolongadas guerras por las independencias, las nuevas naciones se hicieron no sólo enunciables sino también visibles a través un discurso resultado de una tensión entre las prescripciones del romanticismo y, en gran medida, de un determinismo climático-geográfico que Humboldt suscribía. En este sentido, el paisajismo

\footnotetext{
${ }^{1}$ Para este tema, véase el artículo sobre Indigenismo publicado en Oxford Encyclopedia: $<$ https://oxfordre.com/latinamericanhistory/view/10.1093/acrefore/9780199366439.001.0001/acr efore-9780199366439-e-68>.

${ }^{2}$ Como el lugar que ocupa el Chimborazo nevado en el escudo nacional ecuatoriano.
} 
promovido por Humboldt fue también un producto cultural en donde se concretó ese proceso de visibilidad latinoamericana. Este proceso, sin embargo, reorganizó y tendió a naturalizar relaciones de poder y de jerarquía sociales. Si como lo ha leído Mary Louis Pratt, el proyecto de Humboldt era fundir la especificidad de la ciencia con la estética de lo sublime (Praat 2008: 121), esa solución también implicó una jerarquía. Si Humboldt escribió, en el prefacio de Cuadros de la naturaleza, que su objetivo era reproducir en el lector «la antigua comunión de la naturaleza con la vida espiritual del hombre» (von Humboldt 2003: 3-4), hoy ya no puede evitarse la pregunta por la vida de cuál hombre, pues como la misma Pratt sostiene, dicha comunión se logra mediante la asimilación de la (otra) cultura en la naturaleza, de manera que se establecía también así el inferior estatus no sólo del mundo natural, sino también del mundo social de la América. Esta solución de Humboldt es coherente, por un lado, con la concepción de la naturaleza que el movimiento romántico promoverá, pero también con las ideas del determinismo climático-geográfico que él suscribía. Si sus observaciones sobre el mundo natural fueron minuciosas, lo es también porque su proyecto lo prescribía: definir regiones geográficas y climáticas porque eran ellas, según creía él, las que determinaban qué formas de vida florecerían.

En su descripción sobre la naturaleza de los habitantes del nuevo mundo, Humboldt sostiene que la civilización de los pueblos es inversamente proporcional a la fertilidad de la tierra que habitan; y argumenta que la rudeza de los altos territorios de América ha forzado el desarrollo de facultades morales en los indios andinos y mesoamericanos que, según Humboldt, formaron una cultura similar a la de China o de Japón. Y por contraste, la fuerza de la vegetación y del clima de las zonas tórridas han perpetuado la miseria y el barbarismo de hordas solitarias. En suma, los salvajes del trópico derivan de una degeneración causada por la presión del medio ambiente, mientras las civilizaciones de los altos valles sólo alcanzan el nivel de las culturas asiáticas, incapaces de producir un genuino florecimiento del espíritu humano. ${ }^{3}$ En este célebre autorretrato eurocentrista, el progreso social y el desarrollo individual estaban reservados para Europa.

A grandes rasgos, la segunda mitad del siglo XIX en América Latina puede describirse como un complejo reacomodo social de expansión industrial desigual, acompañado por un proceso de redefinición de discursos identitarios, como lo muestra la misma historia del término América Latina (Quijada 1998) Esta racialización del continente tuvo un correlato local en las diferentes historias nacionales, como aquella figuración entre Civilización y Barbarie en el cono sur, o, en el norte, lo que el historiador mexicano Federico Navarrete ha llamado, «la gran confluencia mexicana», término que le sirve para desmontar y criticar esa otra forma de racialización promovida por el nacionalismo revolucionario mexicano a través del término mestizo, un mito que articuló una exitosa narrativa

\footnotetext{
${ }^{3}$ Este tema ha sido analizado en The First America por Brading (1993: 525).
} 
histórica cuyo producto más visible es acaso el muralismo mexicano (Navarrete 2016: 125).

Desde luego que no es extraño que en el Perú surgiera un proceso similar que tratara de fortalecer un mismo proyecto de estado nación durante el siglo XIX, en donde las divisiones políticas y sociales tomaron la forma aparente de la geografía y de la historia: En la dimensión espacial, la costa versus la sierra, la hispanidad junto al mar y opuesta al indigenismo de la sierra; ${ }^{4}$ y en el horizonte temporal (que no histórico), la colonia ante el pasado prehispánico, una división auspiciada y fomentada por las ideas raciales que durante el siglo XIX se habían consolidado en Europa y que la expansión europea contribuyó a difundir por todas partes. Hacía finales del siglo XIX, cuando el positivismo recorría el continente, no era extraño oír, entre los círculos intelectuales de la capital peruana, la pregunta sobre qué hacer con el «problema» indígena; cómo integrar, se preguntaban muchos, a la población indígena dentro de la deseada modernidad de la patria. ${ }^{5}$

La configuración del paisaje en el Perú, y en especial el de la sierra andina, tiene especial importancia por la racialización a la que ha estado sometido y por el papel que esa racialización ha ocupado en la idea de la nación. El lugar privilegiado, aunque tal vez inseguro de las élites hispanoamericanas, aquellas que escribían, publicaban y gobernaban, puede caracterizarse por su dependencia cultural hacia Europa, pero también por la manera particular en que resolverán su propia diferencia, su particular discurso de periferia. Si Europa, es decir, Humboldt, el romanticismo, la ciencia, la pintura del paisaje y enseguida el invento de la fotografía, habían hecho visible el paisaje latinoamericano con una fuerza e independencia nunca antes vista a principios del XIX, muy pronto una segunda espectacularización internacional del paisaje llegó a Perú a principios del siglo veinte. Esta vez, como resultado de la alianza entre las exploraciones científicas y el turismo que se va haciendo posible con nuevos medios de comunicación. Entre 1900 y 1908 se habían construido nuevos ferrocarriles que facilitaron el acceso a la región andina. En Cuzco ya se había vislumbrado el potencial turístico. En 1905 se publicó la guía ilustrada El Cuzco y sus ruinas, de Hildebrando Fuentes. Y finalmente las expectativas de la nueva industria turística se verían potenciadas con la expedición de la Universidad de YALE, es decir, la difusión internacional de Machu Picchu a partir de 1911.

\footnotetext{
${ }^{4}$ Esta oposición es más compleja porque, aunque el hispanismo tuvo sin duda su base en Lima, hubo un indigenismo limeño (Mariátegui) y un indigenismo andino con un fuerte componente regional (Cuzco, Puno).

${ }^{5}$ Sobre este punto, léase el Prólogo de Raúl Porras Barrenechea (Riva Agüero 1955: XXIXXXXIII).
} 


\section{PAisajes PERUANOS}

Es difícil no suponer una relación más que casual entre este contexto tecnológico y por lo menos pre turístico y el viaje que hacia 1912, el historiador y escritor limeño José de La Riva Agüero, nacido hacia 1885 en el seno de una familia acomodada, realizó por la sierra andina, viaje que serviría para producir, años más tarde, un libro seminal en la literatura peruana: Paisajes peruanos. Completado hacia 1917 y publicado fragmentariamente en diarios desde 1916, el libro solo se editó póstumamente hacia 1955. Se trata de un libro que sintetiza una versión del indigenismo hecha desde el conservadurismo nacionalista en Lima. Riva Agüero fue un historiador que más bien ejerció la nostalgia de un destino de grandeza, y cuya visión de la historia nacional distingue en realidad sólo dos épocas clásicas del Perú: la grandeza del imperio Inca y la centralidad de Lima en el periodo colonial. Así, el territorio que él recorre por la sierra es más bien un paisaje republicano trunco, las ruinas de un proyecto de grandeza interrumpido por una prematura independencia. Esta descripción del mundo indígena, (que es más bien una narración mitológica) construye en el paisaje de la sierra una otredad esencial para la patria: no duda en enunciar que el corazón de la patria es la sierra y que algún día volverá a serlo, aunque lo haga desde un orgullo que él identifica como castellano. Si «el Perú moderno vive de dos patrimonios: del castellano y del incaico», Riva Agüero propone superar esta oposición con una solución que integre ese patrimonio incaico al castellano:

No desconozco los inconvenientes del poliglotismo o variedad de lenguas en una nacionalidad, ni lo artificial que sería la reanimación erudita del quechua; pero siendo ilusorio esperar su rápida extinción y la total castellanización de los aborígenes, el elemento educado y superior del país debe inclinarse hacia el indio, ya que éste no tiene fuerzas para subir hasta él, y no olvidar, en la tarea de aproximación, que es la verdadera reconstitución de la patria, el eficacísimo instrumento del idioma, llave de la confianza. (Riva Agüero 1995: 31)

El libro de Riva Agüero es también un extenso retablo de indudable influencia modernista, y como tal, muestra a su vez un esfuerzo por servirse de todas las artes, de presentarse como un texto eminentemente artístico y cívico. En especial, el intensivo uso de imágenes y metáforas potencia su carácter visual. Este pasaje, que ofrece una visión panorámica de Cuzco, antigua capital del Imperio Inca, ilustra la aspiración historicista de su punto de vista:

Repitiendo vagamente los citados textos históricos, hice alto para despedirme de la vieja población, emperatriz destronada de infaustos destinos. Me he iniciado en el encanto fúnebre de sus monumentos caducos, y he aquilatado y enriquecido mis sentimientos de nacionalidad con las imágenes de su magnífica desolación. Hoy, en la soleada y fresca mañana, la emoción final que deja en mi ánimo no es la que generalmente produce, no es la melancolía penetrante de su abandono, el siniestro vencimiento de sus murallas ciclópeas, disgregadas y truncas. Visto de esta altura y a esta hora, el panorama del Cuzco, 
lejos de ser lúgubre, es de una grave y fuerte serenidad casi gozosa, de una clara robustez, comparable a un acorde rico y viril. (Riva Agüero 1994: 14)

A través del libro de Riva Agüero circula una tesis mito-históricista: la grandeza del Imperio Inca fue, mediante su derrota, absorbida, sublimada y superada por la centralidad Colonial del virreinato de Lima. Y el correlato de este discurso es el desplazamiento de la figura del indio hacia un tiempo mítico, ya sea el pasado o, hacia el futuro, la promesa; pero nunca el presente. Cuando la figura del indio aparece en el presente del texto, lo hace como personaje ancilar, circunscrito a la servidumbre, a los preparativos del viaje o a la figura lejana y triste, más que sin un lugar, sin un tiempo. En las casi diez páginas del primer apartado, «Salida del Cuzco», una evocación lírica de amplias frases y ampulosa descripción de la ciudad, la figura del indio aparece solo una vez, apenas con la consistencia de una música lejana ante un oído inatento:

Partí del Cuzco el sábado 1 de Junio de 1912. La mañana era alegre y radiante, de aporcelanada limpidez. En el vecino convento de Santa Teresa celebraban con repiques y cohetes una profesión de monja. Como era la estación seca, el claro invierno serrano, la luz brillaba en la cal de las paredes, chispeaba en los guijarros del piso y en el cauce seco del Huatanay, y cubría con toques dorados la terrosa miseria de los escombros y basurales que ocupan el derruido solar del antiguo Obispo Mendoza, inmediato a mi alojamiento. Transitaba algunas devotas arrebujadas en poñolones obscuros, que se dirigían a la fiesta próxima; y un indio de gorro colorado arriaba una recua de llamas hacia la plaza Mayor. Las mulas, atadas junto a la puerta, se impacientaban con la espera. Al fin, concluidos los preparativos, nuestra cabalgata se puso en marcha. (Riva Agüero 1995[1955]: 9)

Esta descripción de Agüero pareciera no muy distante a la que algo más de cien años antes hiciera Alexander von Humboldt recorriendo la sierra andina:

Los granjeros, con la ayuda de sus esclavos, abrieron un camino entre la maleza hasta la primera caída del rio Juagua... Cuando el acantilado era tan angosto que no había lugar para nuestro propio pie, descendíamos al torrente, cruzando por las partes menos hondas o en los hombros de un esclavo, para luego subir hasta el otro lado del muro... Y entre más avanzábamos, la vegetación se hacía impenetrable, en muchos lugares las raíces de los árboles habían reventado las rocas e incrustado entre las placas del terreno. Tuvimos algunas dificultades cargando las plantas que íbamos recolectando a cada paso... Los indios hicieron incisiones con sus largos cuchillos en los troncos de los árboles y atrajeron nuestra atención en aquellos bellos maderas rojas y doradas, que un día serán descubiertas por nuestros ebanistas y artesanos. (citado en Pratt 2008: 125-127)

Marie Louis Pratt ha señalado que, aunque el discurso de Humboldt sobre la naturaleza es nuevo comparado con los escritos científicos de su tiempo, lo que aún comparte, sin embargo, es la subordinación de lo humano otro. Su objetivo era, sostiene el mismo Humboldt en el prefacio de sus Cuadros de la naturaleza, reproducir en el lector «la antigua comunión de la naturaleza con la vida espiritual del hombre» (Pratt 2008: 122). Sin embargo, esta comunión no incluyó, como se puede inferir, a todos los hombres, pues exterioriza al indio para asimilarlo al otro extremo de la reconciliación, adentro del mundo natural y del 
inferior estatus del mundo indígena. ${ }^{6}$ En el caso de Riva Agüero, la figura del indio no es integrada a la naturaleza, sino a un relato histórico-mítico, de la patria, subsumido como pasado de grandeza, y reminiscencia actual, al destino de la nación.

\title{
3. NOTAS SOBRE EL PAISAJE DE LA SIERRA
}

Notas sobre el paisaje de la sierra ocupa un lugar atípico (pero no contradictorio) dentro de la obra de Mariano Iberico, quien es conocido sobre todo como un filósofo inscrito dentro del movimiento espiritualista en Perú, influido por el filósofo francés Henri Bergson y difusor en el idioma español de los trabajos de otro filósofo también influido por Bergson: Gastón Bachelard. Esta influencia está presente en sus trabajos de crítica y de teoría. Por ejemplo, en un ensayo que Iberico dedicó al estudio de la metáfora y en donde postula un «conocimiento metafórico», que él define como un conocimiento intuitivo que conoce la realidad dentro del alma, siguiendo en esto claramente el método intuitivo de Bergson (1999: 13-20).

Lo singular de Notas sobre el paisaje de la sierra es que, aunque la reflexión está presente, Iberico no lo propone como un trabajo ni de crítica ni de teoría, aunque la influencia de Bergson sí persiste. El libro intenta ser más bien la práctica de esas teorías, un trabajo poético: entre la reflexión y la enunciación poética, entre la descripción de un cuadro concreto y su abstracción. Así, aunque el libro está dividido en lo que él llama imágenes arquetípicas (ríos, nubes, montañas, flores) también advierte:

\begin{abstract}
Y aquí se requieren algunas palabras que expliquen el contenido forzosamente limitado de estas páginas. Sólo se trata en ellas de algunos grandes temas del paisaje serrano: los ríos, las nubes, los cerros, etc. Y así la emoción que las alienta tiene algo de abstracto. No he realizado la labor de artista que consistiría en proyectar cuadros concretos, individuales, inconfundibles. He procurado más bien destacar las imágenes tipo, las apariencias más o menos constantes, los gestos representativos del panorama de la sierra. Y dudo mucho haber logrado sugerir, en lo constante, lo fugaz y en lo fugaz, lo constante, la esencia de la fantasía cósmica que en ese panorama se revela. (Iberico 1973: 13)
\end{abstract}

Por un lado, esta introducción a su libro enuncia ese carácter liminar entre la teoría y la práctica, pues, aunque Iberico se dice renuente a que se le atribuya «la labor del artista», tampoco la rechaza del todo. ${ }^{7}$ De hecho, el libro puede ser

\footnotetext{
${ }^{6} \mathrm{El}$ correlato de esta aserción son las teorías del determinismo geográfico que estaban en boga en ese momento, y que Humboldt siguió y reprodujo. Como se puede ver en el libro de Nell Irvin Painter, The History of White People (2010), los hermanos Humboldt fueron discípulos de Johann Friedrich Blumenbach, a quien se debe una de las enunciaciones «científicas» más célebres acerca de la superioridad racial europea.

${ }^{7}$ En el último párrafo de la misma introducción, Iberico escribió: «Otros escritores peruanos se han ocupado del paisaje serrano. Yo no pretendo igualarlos, pero me uno a ellos en el
} 
visto como una meditación sobre el paisaje andino que recuerda la manera en que Bachelard caracterizó su poética del espacio, como «un estudio del fenómeno de la imagen poética cuando la imagen emerge a la conciencia como un producto directo del corazón del alma» (Bachelard 2000: 9). Notas sobre el paisaje de la sierra está construido mediante representaciones basadas en imágenes; y a la manera de Bachelard, Iberico_también propone un conocimiento metafísico, es decir, un conocimiento que implica una crítica al racionalismo filosófico mediante una defensa a la intuición como método filosófico. Iberico postula que

la verdadera metafísica consiste en una exploración intelectual en donde uno puede sentir el movimiento del alma, y que el instinto es el acto consciente que vuelve a las líneas interiores de la vida. (Iberico 1973: 85)

Por otro lado, si retomamos aquel rasgo que Pratt califica como «dimensión apropiativa» de las historias naturales que aparecieron con la Ilustración, y lo usamos para cuestionar el método de Iberico, nos encontramos con que esta búsqueda por la esencia abstracta (y por lo tanto trans-histórica) del paisaje de la sierra, lo conduce a exhibir un rasgo similar: su potencial para subsumir cultura e historia dentro de la naturaleza (Pratt 2008: 121-122). Esto, que no es explícito en la introducción de su libro, se presenta más adelante, cuando luego de los ríos, las piedras y la noche, aparece la figura del «indio», imagen que se presenta como otro elemento «natural» del paisaje de la sierra.

Iberico, por su parte, representa el paisaje de los andes como una región metafísica para postular un orden trascendental. Y para lograr esto, «naturaliza» también la imagen del «indio»:

La música del indio parece que brotara, no tanto del Corazón dolorido de una raza, cuanto de la desolación del paisaje. (Iberico 1973: 51)

Y más adelante:

Los indios, encogidos y herméticos, pierden su mirada sin luz en una lejanía sin esperanza o vagan como sombras con sus rebaños silenciosos entre los pastos amarillos y mustios. Es la vida en su límite extremo, la vida que no es lucha ni ambición, ni porfía, ni placer, ni dolor sino algo así como un olvido o como una condescendencia de la muerte. (Iberico 1973: 54)

La figura del indio no alcanza aquí el estatuto de una subjetividad, y mucho menos el de un sujeto histórico, sino que se integra al paisaje, entendido éste como la parte visible de la naturaleza, un rostro metafísico. El indio participa apenas de la vida, en una zona liminar, despojada no sólo de razón, sino incluso de pasiones, no en un antes remoto y glorioso, sino como un final o un residuo, cerca ya del olvido y de la muerte.

reverente homenaje al alma enigmática que se configura en la pétrea fisonomía de la sierra» (1973: 9). 
Pensemos ahora el discurso de Iberico en dos niveles semióticos: en el lugar de lo enunciado y en el de la enunciación. Al nivel de lo enunciado, el indio es localizado en un espacio diferente de quien enuncia, una zona metafísica e intemporal, es decir, ahistórica. En el otro nivel, en el lugar de la enunciación, el sujeto habla desde una zona firme y delimitada. Esta localización del discurso se hace evidente más adelante, cuando Iberico establece un «nosotros»:

También nosotros tenemos nuestro oriente, nuestra Asia donde se refugian nuestros sueños falaces de opulencia, de misterio y de fábula: la montaña. (Iberico 1973: 93)

De esta manera el observador, el enunciante, se incluye en una - otraversión del Occidente, se postula como metrópoli que exterioriza el paisaje de la sierra. Se trata de la configuración de un interior, una zona de seguridad que no concede a la otredad el estatuto cultural de un «ellos», sino que la integra a la naturaleza, la figura del indio como una emanación del paisaje. La operación lógica que subyace bajo esta representación también se conoce, precisamente, como actitud orientalista, y Edward Said la definió así:

Comparte con la magia y con la mitología la auto-contención, el carácter centrípeto de un sistema cerrado, en donde los objetos son lo que son, de una vez y para siempre, por razones ontológicas que ningún material empírico puede desplazar o alterar. (Said 1979: 70)

Entre la actitud orientalista caracterizada por Said y la dimensión apropiativa definida por Marie Louis Pratt, hay una propiedad que también fue común al romanticismo: su potencial para subsumir cultura e historia dentro de la naturaleza. ${ }^{8} \mathrm{Y}$ este potencial parece ser uno de los componentes más perseverantes del concepto de paisaje, una de sus coordenadas intensivas que parece, históricamente, recorrerlo. ${ }^{9}$

Vale la pena, por último, sugerir el lugar problemático del concepto de paisaje, que parece siempre oscilar entre el mito y la historia. Esta condición ha sido observada por W. J. Mitchell, en su trabajo sobre Imperial Landscape, en donde apuntó:

${ }^{8}$ De Coleridge a Baudelaire, el poeta romántico asume su misión como un visionario y creador de los símbolos que nos reúnen con la naturaleza.

${ }_{9}$ Deleuze y Gattari observan que la historicidad es condición de todo concepto, aunque también lo es su consistencia intemporal: «El concepto es incorpóreo, aunque se encarne o se efectúe en los cuerpos. Pero precisamente no se confunde con el estado de cosas en que se efectúa. Carece de coordenadas espaciotemporales, sólo tiene coordenadas intensivas... El concepto se define por la inseparabilidad de un número finito de componentes heterogéneos recorridos por un punto en sobrevuelo absoluto, a velocidad infinita» (Deleuze y Guattari 1994: 25). 
Como el dinero, el paisaje es un jeroglífico social que oculta la verdadera base de su valor; y lo hace naturalizando sus convenciones y convencionalizando su naturaleza. (Mitchell 2002: 5)

En la teoría de Jean Luc Nancy encontramos un ejemplo que comparte con el romanticismo su carácter mitológico. Para él, la contemplación del paisaje es la visión utópica, una forma de acceder a lo que permanece inaccesible:

Es inaccesible no porque estaría oculto por las nubes, la vegetación o el cauce de los ríos, sino porque es, desde un exterior y para siempre, más allá y en este lado del acceso: efectivamente, es acceso mismo, es el primer paso del paisaje, la medida de la imagen -ya sean en canvas o en una pantalla, en verso o en prosa, o incluso en música (de alguna manera, ¿no hay siempre paisaje en la música y viceversa?). Esta medida es la medida artística y filosófica por excelencia, la medida que define lo infinito en lo finito. (Nancy 2005: 62)

Al postular en el paisaje una zona que permanece inaccesible, Nancy se aproxima a la zona metafísica que Iberico vio en el paisaje de la sierra. La noción de paisaje en Mariano Iberico implica una operación naturalista (esencialista), ya sea como actitud «orientalista» (Said), o ya sea como una «dimensión apropiativa» (Pratt). Así, más allá de la disputa entre los paisanos por una idea de la nación, el concepto de paisaje parece históricamente condicionado por ese hábito ahistórico: exhibe su potencial para subsumir cultura dentro de naturaleza, y ofrecer una versión de la naturaleza como un orden inaccesible e intemporal, un más allá metafísico, un sistema cerrado e inalterable. ${ }^{10}$ Lo que sugiere Nancy, sin embargo, es que dicha caracterización corresponde a una forma de la mirada que conocemos como paisaje, intrínseca, según él, a la historia europea de la Ilustración (expulsión de los dioses y de las princesas) y del concepto de paisaje. Lo que sugiere Nancy como una virtud ideal, como esa medida artística y filosófica por excelencia, es también en donde radica su problemática, la inestabilidad del concepto de paisaje que lo mantiene oscilando en una zona liminar entre la Historia y el mito, como si su raigambre romántica lo reclamara aún.

\section{CHAMBI Y EL PAISAJE: ENTRE EL PAÍS Y LOS PAISANOS}

Para este trabajo me he apoyado en la propuesta de W. J. T. Mitchell sobre las relaciones entre poder y paisaje, para pensar en el paisaje no como en un sustantivo, sino como en un verbo; no como un cuadro o una concreción estética, sino analizando cómo es usado y qué produce, explorando las imágenes literarias y fotográficas no como objetos, sino más bien como prácticas culturales en donde el paisaje es un proceso dinámico que produce identidades sociales e

\footnotetext{
${ }^{10}$ La anti naturaleza, estudio de Clement Rosset, es un análisis de esta visión de la naturaleza como una realidad trascendental.
} 
individuales; de esta manera interrogaré ciertas modalidades de esos discursos identitarios que, propongo, pueden ser leídos como representaciones ahistóricas del paisaje andino. Por otro lado, utilizaré también una estructura analítica propuesta por Jean Luc Nancy, que distingue entre país, paisano y paisaje. El contraste entre estas dos elaboraciones teóricas servirá para resaltar la tensión entre una crítica histórica del paisaje, por un lado, y la reificación ahistórica de la imagen mítica de la identidad de la sierra andina.

Conviene comenzar con unas palabras del mismo Martín Chambi, extraídas de una entrevista publicada en la Revista Hoy, el 4 de marzo de 1936:

\begin{abstract}
He leído que en Chile se cree que los indios no tienen cultura, que son bárbaros, que tienen una inferioridad mental y expresiva notables al lado de los blancos y europeos. Yo nunca he creído en eso porque conozco a mis hermanos de raza y a los otros. Pero me parece que más elocuente que una opinión, son los testimonios gráficos. Llevo en mi archivo más de doscientas fotografías de diversos aspectos de la cultura quechua. He recorrido y recorreré las regiones andinas del Perú en esta peregrinación. Sobre todo, he escudriñado con la lente de mi máquina fotográfica todos los rincones de los palacios y fortalezas del Cuzco; toda la región en que floreció el Imperio. Aquí están las escenas de hoy. Aquí el mestizaje colonial. Me gustaría que los testigos imparciales y objetivos vieran este acervo. Me siento como representante de la raza. Ella habla en mis fotografías. (Chambi 1936: 1)
\end{abstract}

Estas declaraciones contienen no sólo el contexto social de la recepción de su obra, además de una rotunda identificación identitaria como sujeto indígena, sino también revelan una clara enunciación de su trabajo, una poética, su concepción de la fotografía como un testimonio objetivo, es decir, como una forma de verdad, la manera en que tecnología (la maquina fotográfica), es a un tiempo ciencia, estética e identidad, la insistencia en que en sus fotografías habla la raza (véase el Archivo Fotográfico Martín Chambi en línea: http://martinchambi.org/en/).

Actualmente Martín Chambi es, podría decirse, una figura canónica no sólo en el Perú, sino también en el ámbito de la fotografía internacional. Se dice de Chambi que su nombre se ha convertido, desde finales de la década de 1970, en un referente clave en la historia de la fotografía. Esto se puede leer, por ejemplo, en el texto de presentación del catálogo que acompañó la exposición organizada por el Museo de Arte de Lima (MALI) en el otoño de 2015. Por otro lado, en el texto de introducción del mismo volumen, la historiadora de arte y curadora de la exposición mencionada, Natalia Majluf, escribió: «Las imágenes de Chambi construyeron la identidad visual del Cuzco del siglo XX» (2015:16). Y más adelante, en un texto sobre la relación entre indigenismo y fotografía, la misma historiadora sostiene:

No cabe duda de que Chambi fue una figura clave - sino acaso la figura decisiva - en la definición de la imagen moderna de lo indio como base de la identidad regional y nacional. (Majluf 2015: 278) 
Estos juicios contienen ya la triada propuesta por Jean Luc Nancy: el país (el cuzco del siglo Xx), el paisano (la imagen moderna de lo indio como base de la identidad regional y nacional), y el paisaje (la identidad visual del Cuzco). Conviene interrogar esta fuerte declaración de Natalia Majluf que parece aludir a los poderes de la imagen: la fijación, definición de la imagen moderna de lo indio, a partir del desarrollo de la fotografía y su contexto social. Ya hemos mencionado que a principios del siglo veinte apareció una conciencia turística en el Cuzco, potenciada por la difusión internacional de Machu Picchu de 1911. Pero, en lo que respecta al desarrollo de la fotografía, es una época en la que el género todavía ocupa una zona vaga de autorización estética. La compleja relación entre la fotografía y la pintura ha sido tema de numerosos estudios. Joel Snyder sostiene que la primera generación de fotógrafos paisajistas dependió de las convenciones del género en la pintura, en especial en su devoción al pintoresquismo. Por otro lado, la fotografía, desde la segunda mitad del siglo XIX, estuvo asociada a un carácter industrial, mecánico y tecnológico, que hacía posible postularla como un producto menos subjetivo, no tanto una representación de la realidad como sí una parte de esa realidad. ¿Porqué, se pregunta Snyder, esa primera generación de fotógrafos estaba ansiosa de aceptar la caracterización de la fotografía como algo mecánico?, y ¿porqué trabajaron para hacer que esas impresiones parecieran menos algo hecho a mano, y más el producto de alta definición que sólo una máquina podía lograr? Porque la profesión servía, propone Snyder, a una comunidad que era en primer lugar una clase media aliada al progreso tecnológico, y que establecía un campo de actividad autónomo, uno ligado no a la imitación de la realidad, sino a la semejanza, es decir, cuyos valores se medían en lo factual, la producción de una verdad que podía constatarse en tanto era el pasivo registro de una vista preexistente (Snyder 2002: 175).

La consideración de clase ha sido también usada por Susan Sontag para analizar la práctica de la fotografía y su alianza con el turismo a principios del siglo veinte. Sontag observa que la fotografía en Europa fue guiada por nociones de lo pintoresco: lo pobre, lo extranjero (es decir la otredad inferior), y lo antiguo. Para Sontag, el carácter depredador de la fotografía es evidente en su alianza con el turismo de la segunda mitad del siglo XIX en los Estados Unidos. Luego de terminado el tren transatlántico en 1869 y abierto así el camino hacia el oeste, vino la colonización de este territorio americano con la fotografía. El caso de los indios americanos, dice Sontag, es el más brutal. Un ejército de turistas llegó hacia finales del siglo XIX, ansiosos por lograr «una buena toma» de la vida india. Esos turistas invadieron la privacidad de los indios, fotografiando objetos y danzas sagradas, pagando si era necesario, para que los indios posaran y ofrecieran material más fotogénico (Sontag 1978: 63).

En tanto el turismo es entendido como un fenómeno internacional, estas consideraciones sobre el desarrollo de la fotografía en Europa y en los Estados Unidos pueden servir para pensar lo que sucedía en Perú. En 1927, Chambi 
exhibió en Lima, bajo el título Motivos andinos, una selección de ochenta ampliaciones centradas en vistas de monumentos históricos y costumbres del sur andino. Gran parte de las copias estaba teñida de rojo, azul o sepia. En esa selección predominaban los paisajes, el género que más claramente vinculaba a la fotografía con las bellas artes, con vistas de Arequipa, Puno y Cuzco. La idea misma de esta zona geográfica como una unidad cultural, era una proposición que ganaba fuerza en el marco de la afirmación regionalista impulsada por escritores y artistas. Las vistas de iglesias y pueblos coloniales incluidas en la exposición no sólo remiten al pintoresquismo paisajista que definía el arte fotográfico por estos años, sino también a una nueva concepción del indigenismo que se iba formando en los medios intelectuales de la región, una versión indigenista opuesta a la de Riva Agüero o Iberico, pero ante la cual el mismo Chambi marcaría su propia diferencia. Si bien es también en esta época cuando los tipos indígenas empiezan a dominar la producción fotográfica del Cuzco, las imágenes de Chambi introducen una nueva mirada al género. Éste no se limitó a fotografiar a los campesinos, arrieros y vendedores indígenas que llegaban a comerciar a la ciudad, sino que recorrió sistemáticamente la región para registrar otro aspecto de la vida cotidiana, uno más bien liberado de la servidumbre del bajo salario urbano, y más bien ligado a la fiesta y al paisaje rural.

Majluf ha señalado que las tomas cuidadosamente escenificadas de tipos indígenas en el estudio que Juan Manuel Figueroa Aznar y otros fotógrafos difundieron por esos años a través de revistas y postales, contrastan radicalmente con las fotografías de Chambi producidas en el campo (Majluf 2015: 278). Y Edward Ranney, uno de los principales promotores de la obra de Chambi en los Estados Unidos, ha sostenido que esas imágenes de la vida campesina en los pequeños poblados surandinos tienen escasos paralelos en la producción del periodo (Ranney 2001: 144). Para Majluf, por primera vez el indio contemporáneo aparece proyectado desde el presente, libre de la asociación forzada con la arquitectura precolombina (Majluf 2015: 278). Aquí yace una diferencia radical entre la figura del indio presentada por Riva Agüero o por Iberico, y esta otra presentada por Chambi, la dimensión temporal que rodea ese mundo «indio», el presente compartido entre quien mira y quien es mirado.

Creo, sin embargo, que esta es una respuesta parcial a la especificidad de la mirada de Chambi. Creo más bien que, si hay elementos que se pueden interpretar como el presente en esas fotografías (tecnología, objetos, escenas de la vida cotidiana), es porque Chambi proyecta una idea de lo indio alejada de la servidumbre y de la marginalidad, y conformada más bien a partir de una forma de gasto o derroche que George Bataille ha identificado como soberanía. ${ }^{11}$

\footnotetext{
${ }^{11}$ Lo que distingue a la soberanía es el consumo de las riquezas, en oposición al trabajo, a la servidumbre, que producen las riquezas sin consumirlas. El soberano consume y no trabaja, mientras que en las antípodas de la soberanía, el esclavo, el hombre sin recursos, trabajan y reducen su consumo a lo necesario, a los productos sin los cuales no podrían subsistir ni trabajar (Bataille 1996: 64).
} 
Chambi dota a sus retratados de un aura de autoridad y de poder, no sometidos a la relación desigual de su explotación urbana como era común en las fotografías de la época, ni como sombras tristes e inertes a la manera en que lo hicieron Riva Agüero o Iberico, sino como dueños, sujetos de un entorno natural o milenario. Por eso es que en sus paisajes abundan las fiestas, las celebraciones y el consumo. Como en el ensayo de Bataille, los indios son soberanos por su capacidad de celebración, es decir, de gasto y derroche. Alison Krogel, en su estudio sobre Comida, poder y resistencia en los andes, ha señalado que la representación de las chicheras en Chambi, las proyecta como sujetos autónomos e independientes (Krogel 2012: 105). ¿De dónde viene esta mirada? ¿Cuál es su arqueología, aquello que la hace posible? La respuesta parece provenir simplemente de la posibilidad de que esa soberanía esté tanto en el ojo que mira como en el sujeto que es mirado. Se trataría entonces de una forma de simpatía que es también empatía, una lente que funciona a la vez, como un espejo. En las imágenes de Chambi la otredad es mismidad. Y cada recuento biográfico apoya esta posibilidad. De él se dice que fue, a un tiempo, un fotógrafo indígena, un intelectual indigenista y un miembro de la pequeña burguesía de Cuzco. Es decir, un individuo que se concebía como un artista, como un indígena, y como un intelectual de clase media.

En su análisis sobre el movimiento indigenista, Majluf sostiene que el indigenismo cuzqueño pasó, a partir de la década de los treinta, de ser un movimiento inserto en el debate político, para ubicarse en un horizonte social más difuso. Se fue apartando del tono crítico, y se fue vinculando a la afirmación cultural. Y en este sentido, su afirmación social combina una promoción cultural intensa, con una cierta posición política que lo ubica como un defensor del status quo cultural. Chambi fue un incansable promotor de todos aquellos productos culturales que identificaba con la identidad del indio, fomentando, como sostiene Majluf, la idea de una continuidad entre el pasado inca y el presente indígena. Este es el caso de la música y de los textiles, ambas formas estéticas que Chambi solía incluir no solo en sus fotografías, sino también en sus exhibiciones. Con Chambi, y con la generación de indigenistas de la región andina en general, la idea de lo indio se irá asimilando alternativamente al aparato de propaganda que acompañó el crecimiento de la industria turística y algunos programas de alianza gubernamental, como la filial peruana del Instituto Indigenista Interamericano. Es sintomático, por ejemplo, el reproche que Chambi recibió de uno de sus aliados más entrañables, el escritor indigenista José Uriel García, principal ideólogo del movimiento neo indianista, y quien había visto en Chambi al tipo representativo de esa identidad: «Físicamente un ejemplar autóctono», pero también un hombre «culto, de temperamento artístico, sencillo y cordial, con la sencillez de las magnas piedras incaicas y la cordialidad de los soleados campos andinos» (Majluf 2015: 281). Hacia fines de los años cuarenta, sin embargo, García cuestionará la obra de Chambi porque consideraba la falta de una visión política y doctrinaria más clara para interpretar al pueblo. García lo urgió a «adentrarse 
más en el pueblo y desechar ese idealismo grato para las clases dominantes» (Majluf 2015: 284). Para entonces, la obra de Chambi se había concentrado en la afirmación y celebración de lo indio, antes que en la denuncia de una marginalidad, más en la celebración de una soberanía que Chambi concebía como inmutable, la encarnación de una imagen milenaria y recuperada en sus fotografías. Y en este sentido, aunque la construcción de la imagen del indio de Chambi es diametralmente opuesta a las imágenes propuestas por José De la Riva Agüero y por Iberico, su constitución lógica es similar: una imagen ahistórica y mítica de la identidad.

Pero la diferencia entre la imagen del indio que se desprende de los libros de Agüero y de Iberico por un lado, y aquella que surge de las fotografías de Chambi, también proviene de la tensión estética en que se desarrolló la obra de Chambi, una tensión entre su trabajo como retratista y como paisajista. En este sentido, las imágenes de Chambi pueden ser vistas como retratos con paisaje y como paisajes con retratos. O para usar los términos de Nancy, como paisano con país y/o país con paisano. En Uncanny Landscape, Nancy sostiene que el género de paisaje aparece cuando absorbe o disuelve todas las presencias dentro de sí: la presencia de los dioses y la de las princesas, pero también la presencia del campesino, por lo menos como figura en diálogo con aquellos antes mencionados (Nancy 2005: 61). El hombre de la tierra, dice Nancy, puede aparecer, pero sólo como un elemento del paisaje. Ha renunciado a su ocupación o la ha perdido, y por eso también puede ser reemplazado por un viajero o un caminante, en cualquier caso, por figuras que están ocupadas con la tierra y con nada más; figuras que la tierra ocupa y retiene, que absorbe dentro de sí:

Deshabitado, el paisaje sólo desplaza, crea extrañeza (uncanny): no hay más comunidad ni vida cívica, pero no es simplemente vida "natural", es la tierra de aquellos que no tienen tierra, que son a su vez extraños, que no son gente, quienes son a un tiempo aquellos que han perdido el camino y aquellos que contemplan el infinito - quizás el infinito extrañamiento. (Nancy 2005: 61)

Para Nancy -y retomando el término de Baudelaire-, lo que contemplamos en el paisaje es un templo que abre un lugar para extraer toda presencia, lugar del cual todos los dioses se han ido y los humanos están siempre por llegar. Y si pensamos las fotografías de Chambi a la luz de esta caracterización, entonces esas imágenes se resisten a ser paisajes. Chambi pareciera invertir los términos de la propuesta de Nancy, integrar el paisaje a un discurso identitario, hacer del paisaje un retrato, subsumir naturaleza e historia en la imagen de un sujeto, imagen igual de mitológica que aquella otra que subsume cultura a naturaleza; Chambi «naturaliza» una imagen del indio, la fija sobre un fondo naturalizado, sobre el territorio y sobre la ruina. De esta manera, Chambi ha fijado la imagen de un sujeto soberano en la identidad del indio, una imagen no menos mitológica, sin embargo, que aquella emanación de la sierra que Iberico enuncia, y no menos elusiva que aquella que Riva Agüero mira en el 
pasado remoto de la nación. Desde polos completamente opuestos, desde la costa los textos y desde la sierra las fotografías, divididos por una reivindicación histórica diferente, los tres discursos comparten una visión mitológica de la historia.

\section{BIBLIOGRAFÍA}

ARCHIVO FOTOGRÁfICO MARTÍN CHAMBI. Lima, 2015. Disponible en:<http://martinchambi.org/en/>.

BACHELARD, G. (2000), La poética del espacio, México, FCE.

BATAiLle, G. (1996), Lo que entiendo por soberanía, Barcelona, Paidós.

BRADING, D. A. (1993), The First America, Cambridge, Cambridge University Press.

BERGSON, H. (1999), Matter and Memory, New York, Zone Books.

RIVA AGÜERO, J. DE LA (1995), Paisajes peruanos,Lima, Universidad Católica del Perú.

DeleuZe, G. Y GuATTARI, F. (1994), ¿Qué es la filosofía? Barcelona, Anagrama. (trad. por Kauf, T., Qu'est-ce, que la Philosophie? Les editions de Minuit, 1991).

DeleuZE, G. y GUATTARI, F. (2006), Bergsonism, New York, Zone Books.

CHAMBI, M. (1936), «Arte. El alma quechua alienta en los cuadros de un artista vernáculo», Revista Hoy (4 de marzo), 1.

Humboldt, A. VON (2003), Cuadros de la naturaleza, Madrid, Libros de la catarata. (trad. por Giner de los Rios, B., Cuadros de la naturaleza, Madrid, Gaspar, 1876).

IBERICO RODRíGUEZ, M. (1973), Notas sobre el paisaje de la sierra, Lima, Ed. PL Villanueva. Krogel, A. (2012), Food, Power, and Resistance in the Andes, Boulder, Lexington Books.

MAJLuF, N. (2015), «Martín Chambi, Fotografía e indigenismo», en Chambi, Majluf, N. y Ramney, E. (eds.), Lima, MALI, 274-293.

Mignolo, W. (2008), The Idea of Latin America, MA, Blackwell Publishing.

Mitchell, W. J. T. (2002), Landscape and Power, Chicago, University of Chicago Press.

NANCY, J. L. (2015), «Uncanny Landscape», en The Ground of the Image (Au fond des images), New York, Fordham University Press. (trad. por Fort, J., Au fond des images, Paris, Éditions Galilée, 2003).

NAVARrete, F. (2016), México Racista. México, Grijalbo.

IRVIN PAINTER, N. (2010), The History of White People, New York, W. W. Norton \& Company Inc.

PRATT, M. L. (2008), Imperial Eyes, New York, Routledge.

QUiJADA, M. (1998), «Sobre el origen y difusión del nombre América Latina», Revista de Indias, LVIII(214), 595-615.

Rosset, C. (1974), La anti naturaleza, Madrid, Taurus. (trad. por Calvo, F., L'anti-nature, Paris, Presses Universitaires de France, 1973).

SAID, E. (1979), Orientalism, New York, Vintage.

SONTAG, S. (1978), On Photography, New York, Farrar, Straus and Giroux.

SNYDER, J. (2002), «Territorial Photography», en Landscape and Power, Mitchell, W. J. T. (ed.), Chicago, University of Chicago, 175-202. 